\title{
A Computer Program for Pore Volume and Pore Area Distribution Calculations from Mercury Porosimeter Data on Particulate or Porous Materials*
}

\author{
HILLAR M. ROOTARE and JUDSON SPENCER \\ Unicersity of Michigar. School of Dentistry, Ann Arbor, Mich. 48104 (L'S.A.)
}

(Received September 27, 1971)

\section{Summary}

A computer program in Fortran IV is described for rapidly determining pore size and pore area distribution calculations from the high pressure mercury. porosineter data. The listing of the program is reproduced as well as the printout of the sample data. Illustrations of the graphic representation of the processed data are giten for two samples of fine cristalline precipizated hydroxyapatite and one carbon black-Spheron 6.

\section{INTRODUCTION}

Mercury porosimetry is a widely used method today for determining macro pore size distributions of porous or powdered substances ${ }^{1-4}$, and can be classified as a "standard" method in conjunction with the nitrogen adsorption method.

As the capabilitics of commercial instruments have been improved by increasing the maximum attainable pressure limits from the initial $3000 \mathrm{psi}^{5}$ to the present $60,000 \mathrm{psi}^{6}$. the method quite often replaced the more elaborate and time consuming gas adsorption method.

At first, the 3000 psi pressure range was satisfactory, because it permits measurements down to $600 \AA$ intruded pore diameter, which is the equivalent starting point for the BJH (Barrett, Joyner, and Halenda method) ${ }^{7}$ pore size distribution calculations from nitrogen adsorption data. Thus, the large pores from $100 \mu \mathrm{m}$ to $600 \AA$ in diameter were measured by mercury porosimeter, and the smaller pores from $600 \AA$ down to $14 \AA$ were measured by nitrogen adsorption ${ }^{8}$. It has been found that a

\footnotetext{
- Paper presented at the second annual meeting of the Fine Particle Society, Georgia Tech, Atlanta, Ga., June 24, 1971.
}

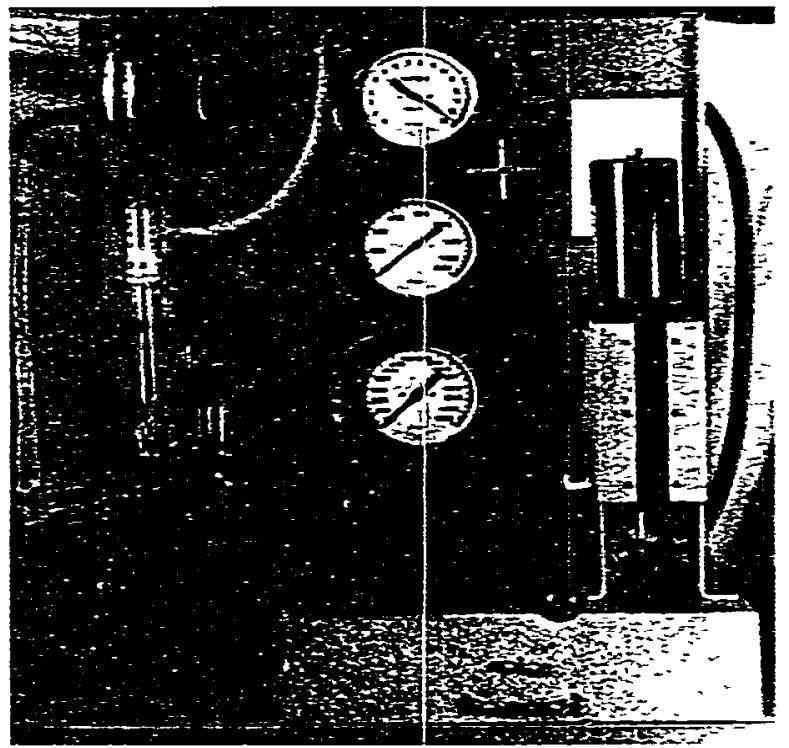

Fig 1. Amince 15,000 psi mercury porosimeter 5-7108. This carly model has been discontinued and has been replaced with a newinstrument that has a motor driven hydraulic pump and digital volume readout.

great number of materials have porosities in the high Angstrom range, which can be intruded by mercury at higher pressures. There has been a demand, therefore, to increase the pressure capability of the mercury porosimeter, thus extending its pore size range downwards. With the increasing awareness of the method and its utility in complementing or substituting for the gas adsorption method, first a 15,000 $\mathrm{psi}^{*}$ porosimeter (see Fig 1)

* Aminco original 15,000 psi porosimeier 5-7108. still used in this laboratory, has been replaced with a new 15,000 psi motordriven and digital readout model 5-7121. American Instrument Co., Silver Spring. Maryland 20910. 


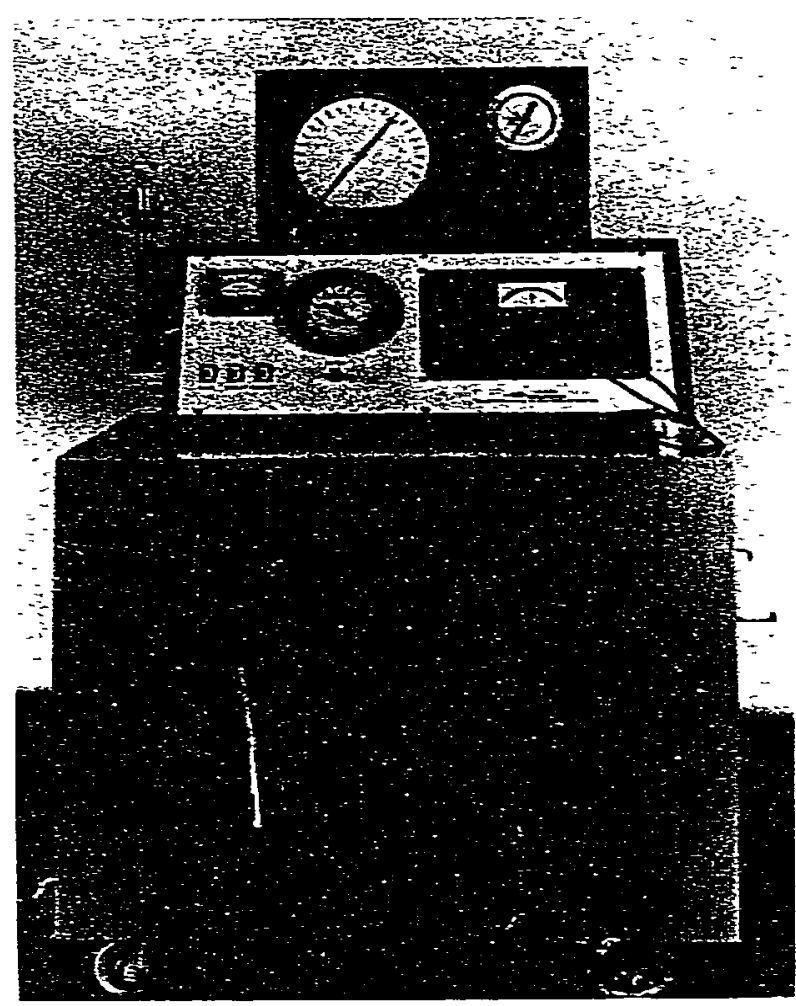

Fig 2 Aminco 60,000 psi mercury forosimeter 5-7125B. This high pressure version uses capacitive readout of the mercury volume displacement.

and then a 60.000 psi* porosimeter (see Fig. 2) were acquired by this laboratory. Other instruments are also available** .

The 60,000 psi mercury porosimeter can cause mercury to penetrate pores as small as $30 \AA$ in diameter, if $130^{\circ}$ is taken as the contact angle between mercury and the solid. It can, therefore, frequently and routinely replace the gas adsorption method for pore size distribution determination of materials as a simpler and more rapid way of obtaining the same information.

* Aminco 60,000 psi porosimeter 5-7125B used in this laboratory.

** Other manufacturers of mercury porosimeters are Carlo Erba Scintific Instruments Division, Via Carlo Imbonati. 24 I 20159 Milano, Italy (porosimeter model 70 has max. pressure $3000 \mathrm{~kg} / \mathrm{cm}^{2}$ and pore range $37.5 \mathrm{~A}$ to $75 \mu \mathrm{m}$ ) and Micromeritics Instrument Corp., 800 Goshen Springs Road, Norctoss, Ga 30071 (porosimeter model 905 has max. pressure 50,000 psi and pore range $35 \AA$ to $177 \mu \mathrm{m}$ ).
Nevertheless, the age of automation has provided those who have the funds with an automated adsorption apparatus-the Adsorptomat" ${ }^{9 *}$. The "raw data" from the automatic adsorption instrument is reduced by the computer into the final form for evaluation. For this reason there has been a drastic reduction in the time and cost of obtaining poresize distribution data by nitrogen adsorption method. However, the same type of information is available in less time and at lower cost by high pressure mercury porosimetry, an independent approach to reach the same objective as gas adsorption. Those who have not decided which way to proceed now have an alternative to consider.

Because of the time-consuming hand calculations involved in the treatment of the "raw data" from the mercury porosimeter, a simple but versatile computer program for the pore-size and pore-area distribution calculations has been developed. Machine instructions have been written in Fortran IV (see Fig 3) for the IBM 1130 computer, which is available at the University of Michigan, School of Dentistry. The program can be readily adapted for use with the IBM 360 or other comparable computers. This program has been successfully used in the analysis of several hundred porosimeter runs, and it has saved hours of labor with the desk calculator. Because of the time requirements, some of the calculations would probably not have been performed at all, if not for the computer (see Figs. 4 and 5).

\section{DESCRIPTION OF PROGRAM}

The compilation of the program is reproduced in Fig. 3. At the end of the program, the first statement lists the number 25 , which is the number of values at which the pore diameters will be listed for the percent volume and area determinations. The next three cards list the actual pore diameter values for which the computer will calculate the corresponding percent pore volume and pore area distributions, which will be listed on the second page of the printout (Fig. 4).

On the fourth card the weight of the same (W) is listed, and the following card lists the title of the run or the sample identification. These cards are followed by the actual data points-four per card.

\footnotetext{
* Adsorptomat 4-4680. American Instrument Co., Silver Spring. Md. 20910.
} 

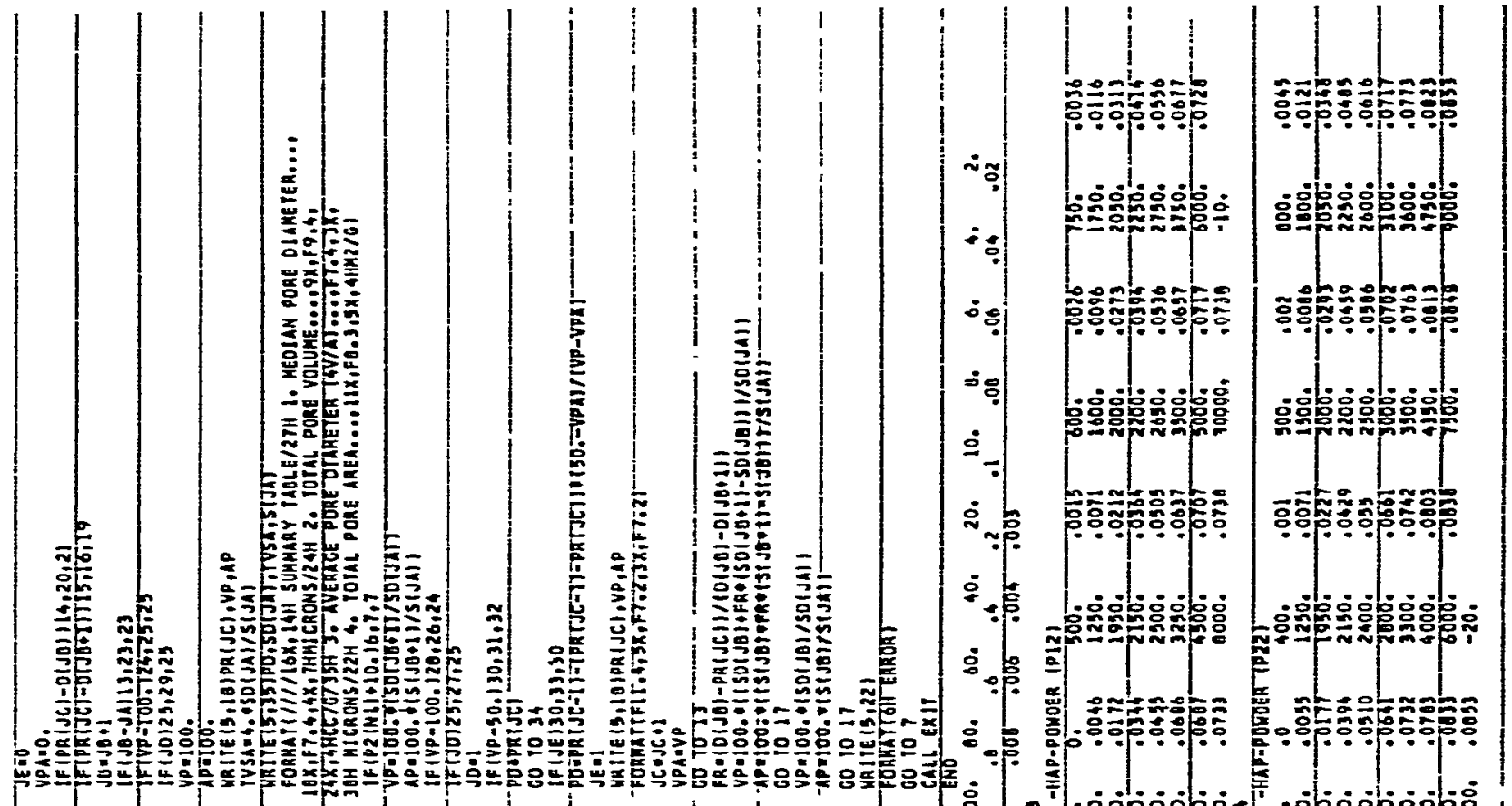

言

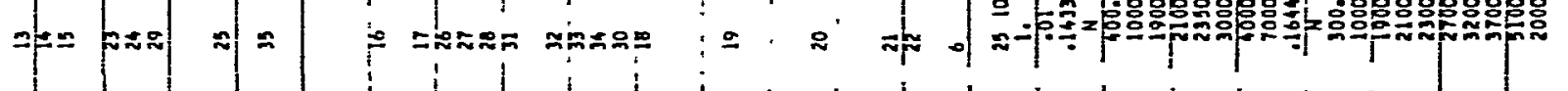

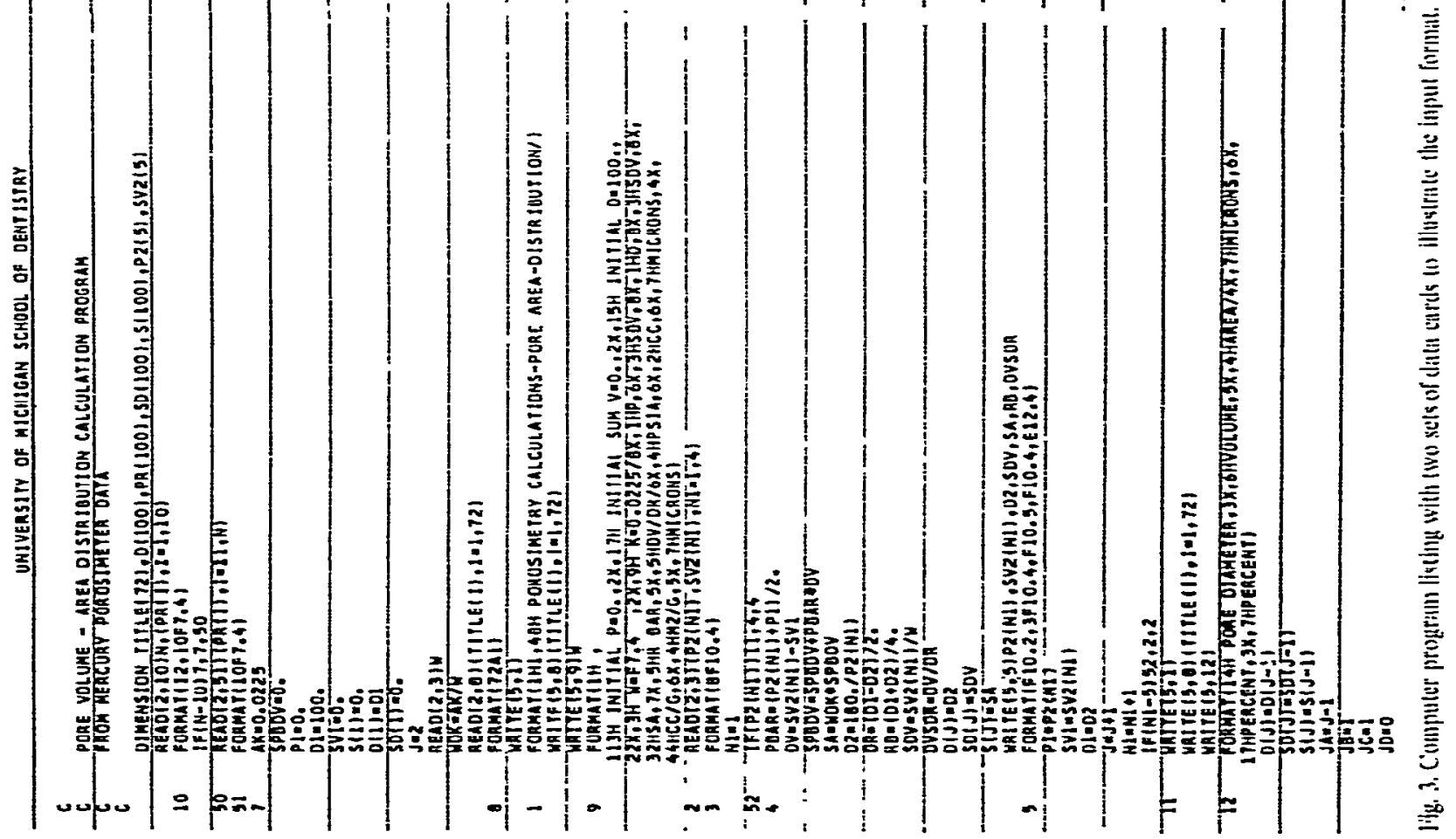

Ponder Technol.. 6 (1972) 

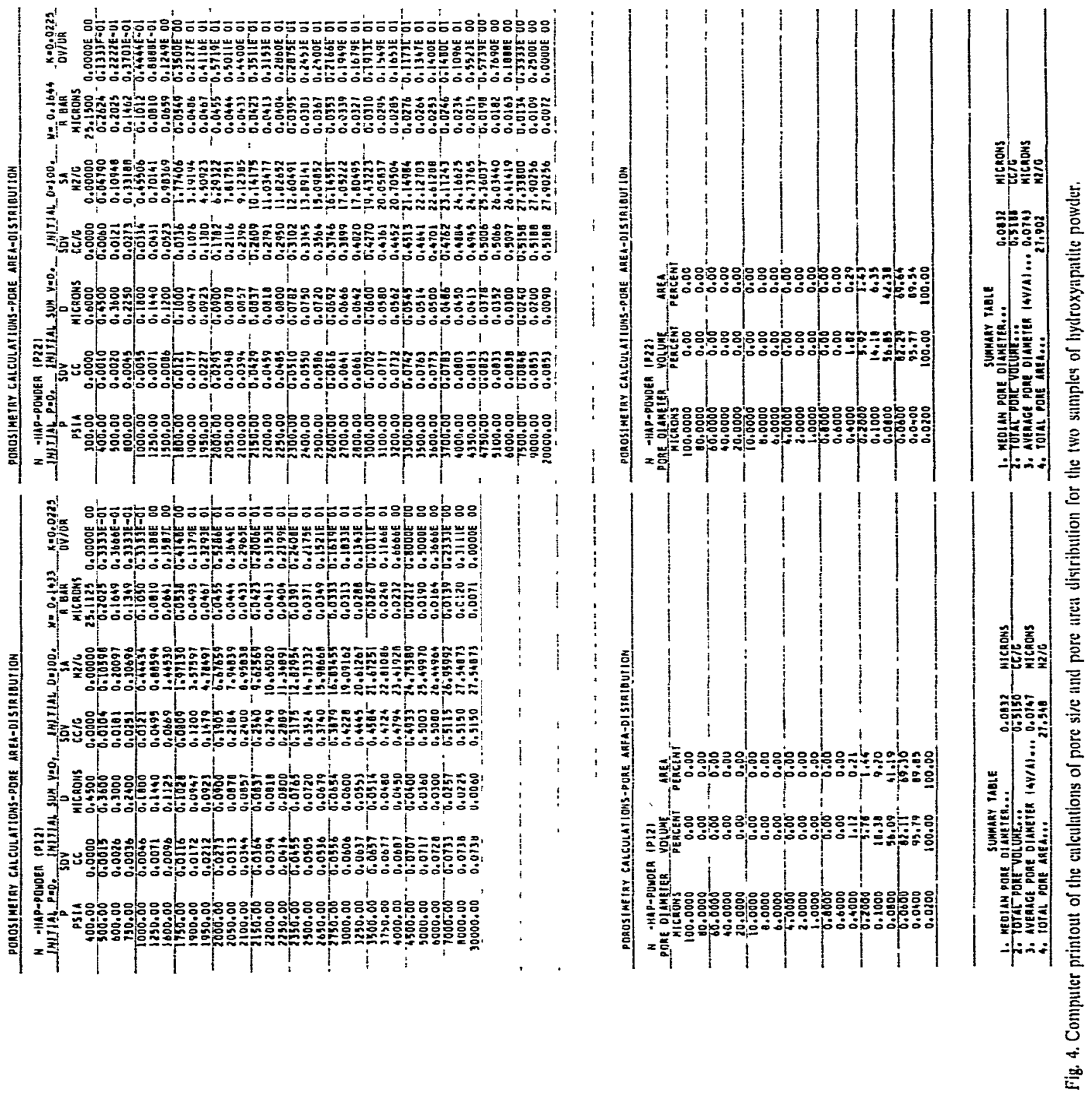

Ponder Technol, 6 (1972) 


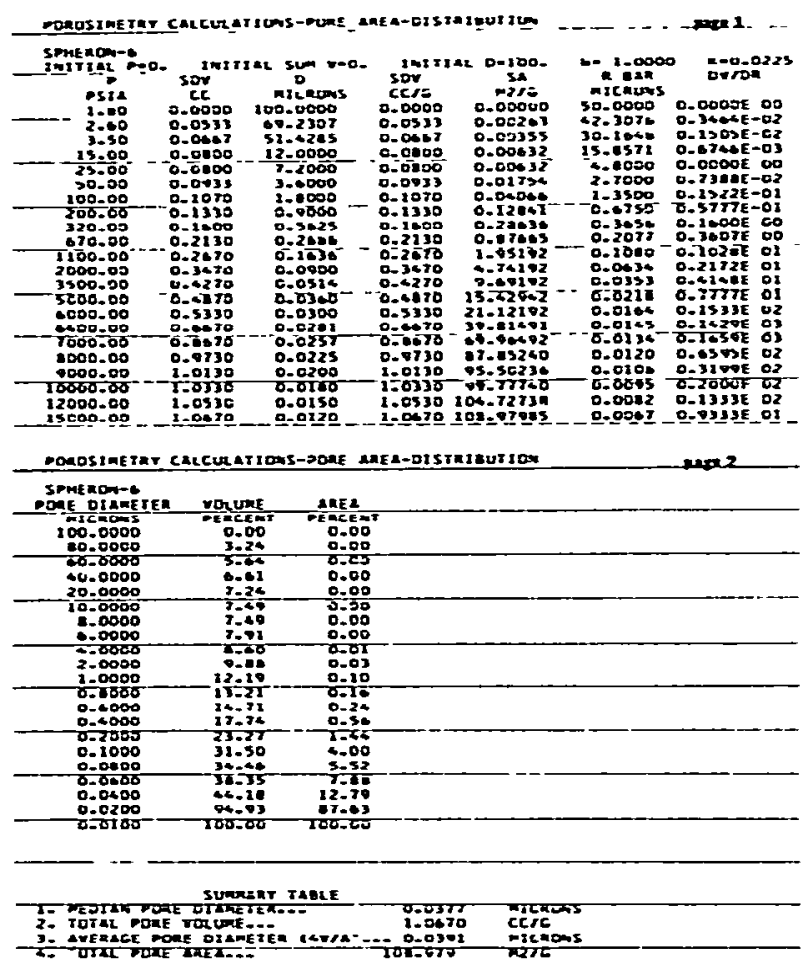

Fig. 5. Computer printoui of the calculations of pore size and pore area distribution for the reference sample number 3. carbon black-Spheron 6.

Each point consists of two values, one for the pressure in psia and the other for the volume in cc. As many points as necessary are listed. All decimal points are punched for the sake of simplicity. The card formats are summarized as follows:

Card Form 1. Cols. 1 \& 2: List the number of pore diameter values (in $\mu \mathrm{m}$ ) to be used for the percent distribution determination. Cols. 3-9, 10-16, 17-23...66-72.

List the values at which pore diameter and the percent pore size distributions are to be determined. If more than one card is required, the next card will have the values listed in columns $1-7$. $8-14,15-21 . .64-70$, and so on.

Card Form 2. Cols. 1-10: List the sample weight (w).

Card Form 3. Cols. 3-80 are used for the title or identification of sample.

Card Form 4. Cols. 1-10, 21-30, 41-50, 61-70 Pressures in psia are listed, and Cols. 11-20, 31-40, $51-60,71-80$ the volumes in $c c$ are listed for the corresponding pressures. Punch all decimal points.

Each succeeding card will look like the above card except for the last data card. That is, each card will contain four pairs of data points. The last card may end with the last pair of data in columns 61-70 and 71-80. If this is the case, another card should be added which has a -10 . in columns $1-4$. If the last pair of data does not occur in the last two columns 61-70 and $71-80$, then -10 . is punched in the first four columns of the ten column field : e.g. if the last pair oî data points occurs in columns $41-50$ and $51-60$, then -10 . is punched in columns $61-64$.

The -10 . is a signal to the program that the end of data has been reached, the computation should be done, and that there is another set of data to be processed following the present set. If it is the final set of data, -20 . should be substituted for -10 . Thus, each set of data starts with the card containing the value of $\mathrm{W}$ and continues through the card containing -10 or -20 . if it is the last set to be processed.

\section{RESULTS}

To illustrate the computer output and to demonstrate the reproducibility of the mercury porosimeter method the printout is reproduced for two different samples of $\mathrm{N}$-hydroxyapatite powder in Fig 4. The printout for reference sample No. 3 . carbon black-Spheron $6^{10 * *}$ is reprodiaced in Fig. 5 . This sample is used by many workers to check the apparatus when measuring BET surface areas with nitrogen. The reported reference value of BET surface area for Spheron 6 is $110 \mathrm{~m}^{2} / \mathrm{g}$. The surface area by mercury porosimeter of $109.0 \mathrm{~m}^{2} / \mathrm{g}$ agrees very well with that of nitrogen adsorption value. The printout consists of two pages; the first page tabulates the original data input in the first two columns, which is followed by columns of corresponding pore diameter (D) in $\mu \mathrm{m}$ and normalized pore volume (SDV) in $c / g$. The pore volume tersus pore diameter is plotted in the top half of Fig. 6 . The fifth column lists the cumulative pore surface area (SA) in $\mathrm{m}^{2} / \mathrm{g}$ (see Fig. 7 for the plot). The last

\footnotetext{
- N-Hydroxyapatite sample was provided by the Physical Pharmacy Dept, School of Pharmacy, University of Michigan. Code letter $\mathbf{N}$ identifies the preparation.

* One of the reference adsorbents for surface area measurements prepared by Bone Char Research Project, Inc at the National Burcau of Standards. The project was terminated 1963. Limited quantitics of samples and the Technicai Repor No. 73 may still be available from the American Instrument Co.. Silver Spring, Md.
} 

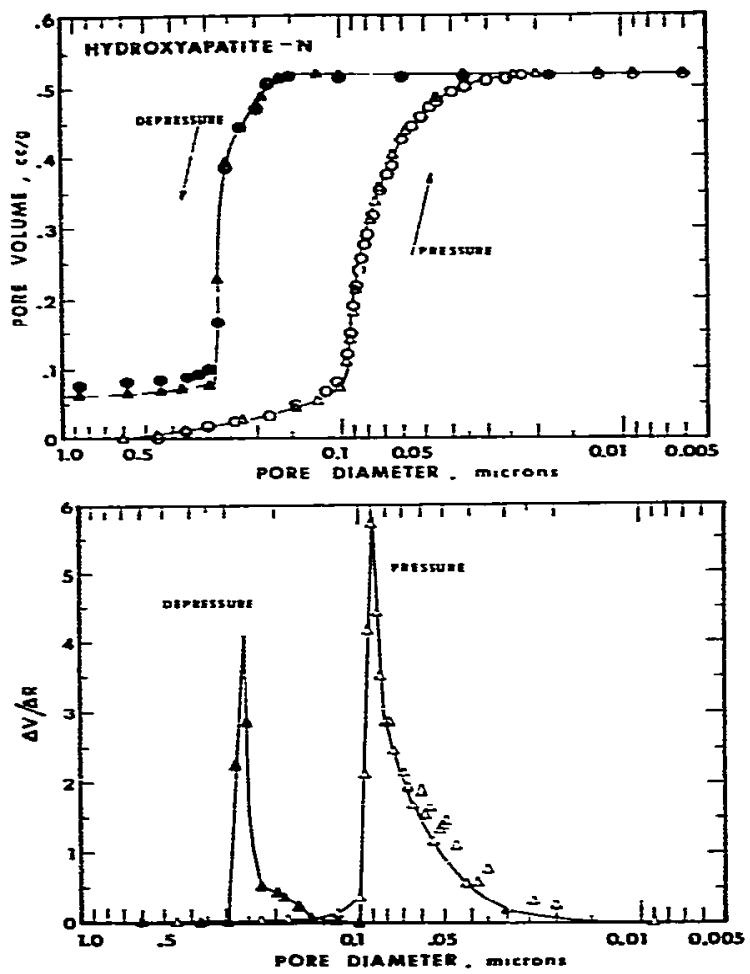

Fig. 6. The top figure shous the pore size distribution in the form of the integral, or the cumulative pore volume $r s$. pore diameter plot for the tho samples of hydroxyapatite samples. $O$ first sample P12 $\triangle$ second sample P22. The bo:tom figure shows the differential distribution curves for both the pressure and the depressure cycle of the sample P22 The curves for the sample Plz are identical.

two columns of the first page list the mean pore radius ( $R$ BAR) in $\mu \mathrm{m}$ with the corresponding differential distribution function (DV/DR) (see Fig. 6 bottom half).

The second page of the computer printout (Figs. 4 and 5 bottom) lists the percent pore volume and the percent pore area distributions for a selected listing of pore diameters. These pore diameter values are arbitrarily chosen and can be changed to suit individual needs by simply changing the numbers listed on the first set of cards that follows the program listing (Look at the Fig. 3 and the format instructions).

For the convenience of the operator, a Summary Table is printed on the bottom of the second page of the printout. It lists the pertinent information for a quick inspection of results. Median and average (4V/A) pore diameters are given together with the

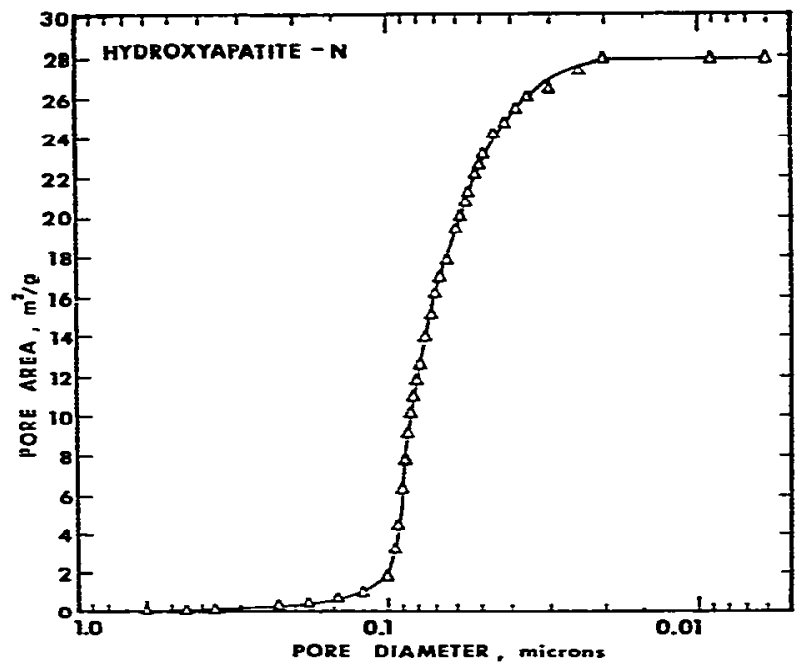

Fig. 7. Pore area $\left(\mathrm{m}^{2} / \mathrm{g}\right)$ plotted as the function of pore diameter for comparison with the pore volume plot of Fig. 3. for the hydroryapatite sample.

total pore volume and the total pore surface area.

Figures 6 and 7 illustrate some of the graphical representations of data available from the computer output. The top half of Fig. 6 is a plot of cumulative pore volume versus pore diameter in $\mu \mathrm{m}$ or the integral pore-size distribution curve for the $\mathrm{N}$ hydroxyapatite. It shows both the pressurization curve and the depressurization curve for the two samples from Fig. 4, indicating the extent of hysteresis resulting from the characteristic shapes of the pores or rather voids formed by the crystallites of the apatite. The openings to the voids are about six times smaller than the diameters of the voids themselves.

The bottom half of Fig. 6 is a differential distribution curve for the sample P22 showing the results from both the pressurization curve and the depressurization curve. At times it may be important to know not only the mean diameter of the opening to the pores, but also the mean diameter of the voids or pores themselves. These data are obtainable within an hour or two, depending on the sample and the availability of the computer service.

Customarily the DV/DR function is plotted versus the mean radius, which is listed in the next to the last column of the printout as R BAR; however, in order to show the coincidence of the peaks of the differential plot with the sharp rises of the integral curves, DV/DR was plotted as a function of pore diameter. 


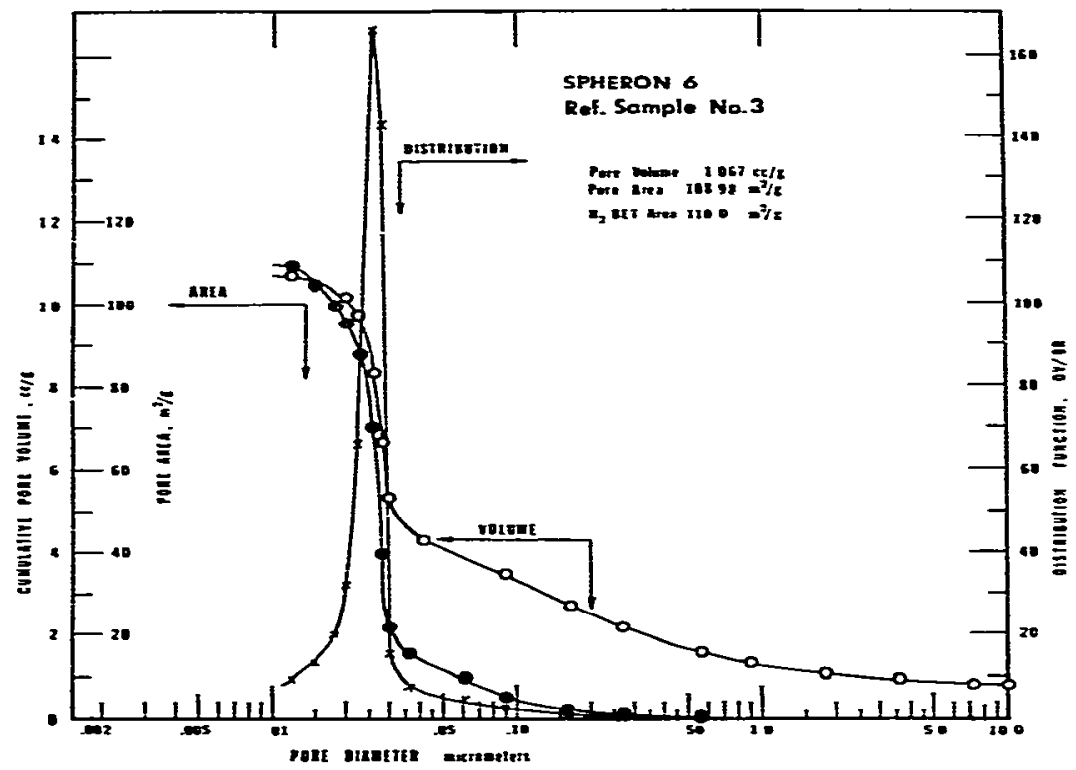

Fig 8. To illustrate three ways of presenting the data calculated by the computer program, the cumulative pore rolume and pore area. as well as the differential distribution function rs. the pore diameter. are plotied on the same graph for Spheron 6.
Pore area distribution is plotted as a function of pore diameter in Fig. 7. Since at times pore area distribution may be of more importance to the investigator studying catalysts than the pore volume distribution, this option is made available by the computer program.

Those who have used Spheron 6 as a reference adsorbent in their work may find Fig. 8 of interest. It is a composite of three curves and is a visual summary of the type of information obtainable by mercury porosimetry. One can quickly observe that the pore volume and the pore area distribution curves are not identical. The smaller pores affect the pore area distribution more than the larger pores. The differential distribution function (DV/DR) shows quite clearly the narrowness and the symmetrical shape of the pore size distribution of the interstitial voids between the particles (in the case of this sample), which may not be as evident from the cumulative pore volume curve.

\section{ACKNOW LEDGEMENTS}

This investigation was supported by United States Public Health Service Training Grant DEO0181 from the National Institute of Dental Research, National Institutes of Health, Bethesda, Md.

\section{REFERENCES}

I H. M. Rootare A shont literature revien of mercury porosimetry as a method of measuring pore-size distributions in materials, and a discussion of possible sources of errors in this method. Aminco Lab. Niens. 24 (Fall 1968) 4A-4H.

2 H. M. Rootare A revieu of mercury porosimetry, in $J . S$ Hirshhorn and $\mathrm{K}$. H. Roll (eds.), Adranced Experimental Techniques in Pouder . Metallurg:, Plenum Press. New York. 1970. pp. 225-252

3 H. M. Rootare and A. C. Nyce, The use of porosimetry in the measurement of pore size distribution in porous materials. Intern. J. Powder Mat- 7 (1971) 3-11.

4 C Orr. Jr. Application of mercury penetration to materials analysis. Powder Technol. 3 (1969;70) 117-123.

5 N. M. Winslow and J. J. Shapiro, An instrument for the measurement of pore-size distribution by mercury penetration. AST.1Y Bull, TP 49 (1959) 39-44.

$6 \mathrm{~L}$. C Drake Pore size distribution in porous materials Application of high pressure metcury porosimeter to cracking catalysts. Ind. Eng. Chem_ 41 (1949) 780-7S5.

7 E P. Barretl L G. Josner and P. P. Halenda. The determination of pore volume and area distributions in porous substances, I. Computations from nitrogen isotherms. $J$. Am. Chem. Soc., 73 (1951) 373-380.

8 J. H. Caro and H. P. Freeman Pore structure of phosphate rock and triple superphosphate J. Agr. Frad Chem, 9 (1961) 182-186.

9 E. V. Ballou and 2. K. Doolen. Automatic apparatus for determination of nitrogen adsorption and desorption isotherms. Anal. Chem 32 (1960) 532-536.

10 V. R. Deitz F. G. Carpenter and H. M. Rootare Reference adsorbents of the Bone Char Research Project, Inc, Tech Rept. No. 73, Intesrigations of Bone Char Research Project. Inc., 18 .19arch, 1963. 